\title{
Impacto de la ingeniería forestal en el manejo de los recursos naturales en Mesoamérica
}

Los bosques tropicales son ecosistemas que brindan a las personas una serie de servicios como agua, biodiversidad, madera, absorción de dióxido de carbono, productos no maderables, dendroenergía y también belleza escénica.

Es por esto que la Ingeniería Forestal cumple un papel importante, ya que no solo promueve la conservación sino que también el desarrollo sostenible de los bosques a nivel mundial. Bajo este concepto, algunos estudios realizados en América Latina y el Caribe, como las propuestas de Reducción de emisiones por deforestación y degradación (REED+) y Legalidad Forestal en Mesoamérica, indican que es cada vez más urgente tener conocimiento científico en el área de las Ciencias Forestales para promover la conservación, uso sostenible, el comercio de los productos forestales y mejorar la gestión forestal, incluso bajo el marco de fuentes legales.

En la Conferencia de las Naciones Unidas sobre el Medio Ambiente y el Desarrollo de 1992, países como México, Costa Rica, Honduras, El Salvador, Guatemala, Panamá y Nicaragua suscribieron una serie de acuerdos que buscan establecer una alianza en materia ambiental y de desarrollo sostenible de los bosques que fomenten la cooperación entre los Estados y la sociedad.

Bajo esta filosofía trabaja la Escuela de Ingeniería Forestal del Instituto Tecnológico de Costa Rica y su
Revista Forestal Mesoamericana Kurú, promoviendo la divulgación de trabajos científicos como los presentados en este volumen y que son aporte de investigadores de Costa Rica, Honduras y Chile. Los cuales van enfocados al aprovechamiento de los bosques con aplicaciones energéticas, de conservación, reproducción de árboles, valuación de clones de especies maderables, productos de ingeniería y análisis de ecosistemas en situación de pre y post-incendio forestal.

Sin duda, estos aportes y los futuros serán insumos importantes para que el desarrollo forestal del país y de la región tenga base sólida para dirigir esfuerzos en consolidar el aprovechamiento y conservación de los bosques de forma sostenible, que es el reto actual que tienen los profesionales en Ingeniería Forestal a nivel mundial. 